\section{SM Dermatology Journal}

\section{Article Information}

Received date: Oct 08, 2017

Accepted date: Nov 03, 2017

Published date: Nov 08, 2017

\section{*Corresponding author}

Annebeth Meij-de Vries, MD, PhD, Burn Center, Red Cross Hospital Beverwijk, Vondellaan 13, 1942 LE Beverwijk, The Netherlands, Email: adevries@rkz.nl

\section{Distributed under Creative Commons} CC-BY 4.0

\section{Keywords Zimmer pneumatic} dermatome; Skin graft; Thickness

Abbreviations LUMC: Leiden University Medical Center; FTSG: Full Thickness Skin Graft; STSG: Split Thickness Skin Graft

\title{
The Dermatome and Its Thickness Setting: What You Set Is Not What You Get
}

\author{
Annebeth Meij-de Vries ${ }^{1 \star}$, Floris E Aartsen ${ }^{2}$, Pieta Krijnen ${ }^{2}$, Dorotka T \\ Roodbergen $^{1}$, Jos FPM Vloemans ${ }^{1}$ and RS Breederveld ${ }^{1,2}$ \\ ${ }^{1}$ Burn Center, Red Cross Hospital Beverwijk, Vondellaan 13, 1942 LE Beverwijk, The Netherlands \\ ${ }^{2}$ Department of Surgery-Traumatology, Leiden University Medical Center, Albinusdreef 2, 2333 ZA Leiden, \\ The Netherlands
}

\section{Abstract}

Background: Skin grafting is a vital part of the treatment of deep skin defects. The preferred thickness of the graft is determined on the parameters of the wound which needs to be covered. Although, it is not known in how far the dial setting of the dermatome corresponds with the actual thickness of the harvested skin graft. To determine the usability of a dermatome setting regarding the resulting grafts thickness.

Methods: During the harvesting of split skin grafts in the operation theatre, the average thickness of harvested skin grafts was compared to the dermatome thickness settings.

Results: A total of 50 grafts were collected from 30 patients, leading to 250 thickness measurements (5 per graft). The measured thickness differed significantly from the dermatome setting: the grafts were up to $50 \%$ thinner than the dial setting when the settings of $0.25 \mathrm{~mm}$ and $0.30 \mathrm{~mm}$ were used. Scalp harvest thickness varied from $50 \%$ thinner to $200 \%$ thicker than the setting. Thickness was more or less constant across the skin grafts both lengthwise and laterally. We did not detect an effect of the blade becoming blunt regarding its accuracy after repeated use.

Conclusion: These results imply that the average measured skin graft thickness is up to $50 \%$ thinner than the thickness setting. Graft shrinkage alone does not seem to pose an adequate explanation for this difference. In scalp harvests, there is more variability in the thickness of the grafts. Furthermore, our results suggest that grafting blades do not have to be changed during the procedure, because we found no signs of bluntness.

\section{Introduction}

Skin grafting is a vital part of the treatment of deep skin defects resulting from burns, necrotizing fasciitis and other causes. Nowadays, Split Thickness Skin Grafts (STSGs), comprising the epidermis and a part of the dermis, are normally harvested with electric or pneumatic dermatomes. STSGs are clinically subdivided into the categories thin, medium and thick, with increasing parts of the dermis being harvested. There are, however, no widely used standard ranges for this subdivision. Some research has been done to determine the clinical advantages and disadvantages of thicker and thinner grafts $[1,2]$. Generally speaking, thick STSGs give better cosmetic results but suffer more from necrosis, whereas thin STSGs need less wound bed vasculature, but are less cosmetically pleasing. Tang [3] found that there are distinct clinical advantages if a surgeon can choose between thicker and thinner STSGs. For example, when vascularization of wound bed is moderate, a thinner STSG is indicated. This is to enlarge the chance of a good take of the STSG. On the other hand, when the location of the split skin transplantation requires a better quality of scar, a thicker STSG will be indicated. This, for example, might be the case when a STSG is used over a joint.

It has long been accepted that surgeons are not capable of harvesting grafts with an exact and constant thickness using dermatomes. This is because; skin thickness varies with anatomical location. Besides, grafts may be harvested from concave and convex body areas. Therefore, it is accepted that the average thickness of skin grafts harvested with dermatomes is related to the thickness setting [4]. However, no studies in the current literature have evaluated the relation between the thickness setting on the dermatome and the actual harvested thickness. Before harvesting, some surgeons run their scalpel through the opening of the dermatome to check its thickness setting, which shows that the dial setting is not universally trusted to provide a set thickness skin graft [5]. However, it has never been studied if surgeons are capable of harvesting such an average thickness using a dermatome. This might be because; it is very difficult to measure the thickness of a skin graft. Many factors conceivably influence the thickness of a skin graft once it has been harvested (e.g. contraction of the graft, and compression of the graft by the measurement tool). Under standardized study conditions, however, one would expect these factors to be constant, and to be able to study the direct relationship between dial settings and actually measured graft thickness. What You Set Is Not What You Get. SM Dermatolog J. 2017; 3(3): 1020. 


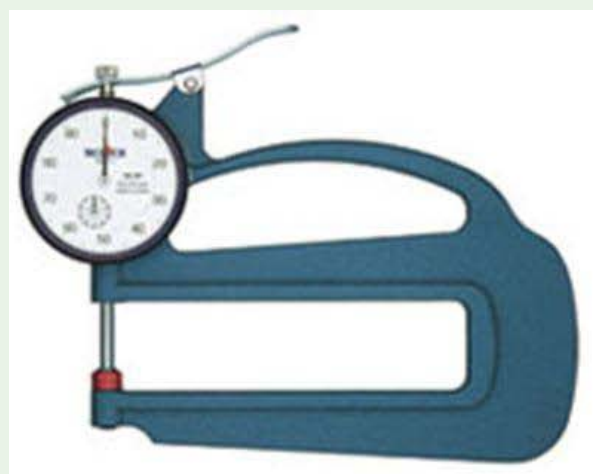

Measurement Range: 0 10mm

Resolution: $0.01 \mathrm{~mm}$.

Probe style: diameter $10 \mathrm{~mm}$ ceramic flat

Measuring force: $2.5 \mathrm{~N}$

Figure 1: The Teclock SM-11, with specifications.

All this leads to our primary research question: is there a difference between the dial setting and the average thickness of the skin graft? Secondly: is the difference between the dial setting and the average thickness consistent across harvest locations? Thirdly: is the shape of individual grafts consistent (i.e. are they flat)? Fourthly: is graft thickness influenced by the repeated use ('bluntness') of the blade?

\section{Materials and Methods}

\section{Study design}

This prospective observational study was performed between February 2016 and August 2016 in the Burn Center of the Red Cross Hospital, Beverwijk, The Netherlands. Included were skin grafts harvested inpatients of all ages used for covering deep skin defects caused by thermal injury, severe skin infections or other causes. Skin grafts shorter than $5 \mathrm{~cm}$ were excluded in order to avoid that multiple measurements would cover the same spot on the graft. Furthermore, skin grafts were excluded from the study at the discretion of the operating surgeon, usually for logistical reasons (e.g. if there was no time to measure the graft thickness during the procedure in the operating room).

\section{Study procedures}

Skin grafts were harvested and transplanted according to the standard operating procedure [1,5]. The dial setting of the dermatome was left to the preference of the surgeon. Of note is the standard operating procedure for scalp grafts, as this differs markedly from that for the other skin grafts. Scalp grafts are harvested in children below the age of ten after subcutaneously infusing the scalp with saline. All grafts in the study, including the scalp grafts, were harvested using one of the seven Zimmer II pneumatic dermatomes with disposable blades available in the operating rooms of the Burn Center in Beverwijk. For the purpose of this study we spread the skin graft out on a single layer of the sterile packaging foil that came with UrgoTul ${ }^{\circ 1}$ and covered it with a second layer, to protect the skin graft from contamination during the measurements. The thickness of the grafts was measured directly after harvesting and before meshing using the Teclock SM-1142 (Figure 1), an analog thickness measuring instrument that is widely used for industrial purposes such as measuring leather, hair, rubber plates, metal pipes and plastic film. The Teclock measuring device has an analog readout dial with a minimal resolution of $0.01 \mathrm{~mm}$. The pressure of the measuring device is a constant $2.5 \mathrm{~N}$ independent of the thickness measured.
After measuring the skin graft, the UrgoTul foil was removed and the graft was processed in the usual way. Since the study did not interfere with the operations and had no effect on the patient or the skin graft, approval from the ethical review board was not necessary and therefore not requested.

All measurements were performed by two observers, who were chosen at random by the operating surgeon, but were nurses from the operating room or a specialized research assistant in most cases. Observers were instructed to set the Teclock to zero before measuring and to round up measurements to the nearest hundredth of a millimeter. Each skin graft was measured at five specific points i.e. on the four corners, 1centimeter from the edge, and in the center of the graft (Figure 2). These points were chosen to be able to calculate a representative average thickness. Additionally, the thickness of the two layers of foil without a graft in between was measured every time a skin graft was measured, to provide thickness data on the foil.

The hammers of the Teclock were gently set on the foil-covered skin graft and the dial was read out after some seconds in order to get a stable measurement. The dial setting of the dermatome was registered and additional data were recorded, including the gender and age of the patient, anatomical location of the graft, names of the surgeons and observers and the width of the dermatome blade. Length of the donor wound and graft were measured to give an indication of the amount of post-harvest shrinkage.

\section{Sample size}

For this validation study no formal sample size calculation was performed, but 50 skin grafts were assumed to be sufficient to draw conclusions on the reliability and validity of the thickness measurements.

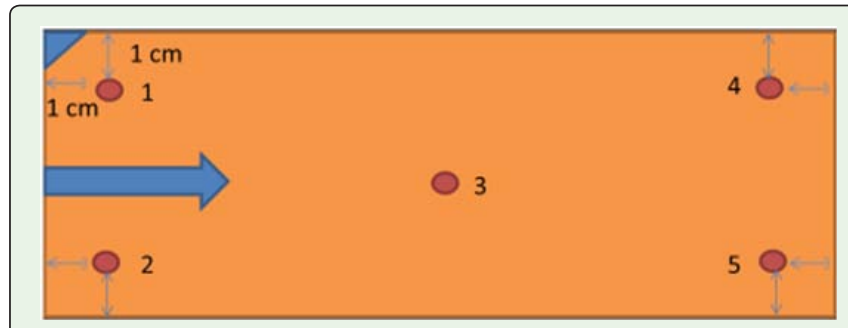

Figure 2: Fixed measuring locations on the graft. 


\section{Statistical analysis}

The data was analyzed using IBM SPSS Statistics for Windows, Version 23(IBM Corp., Armonk, N.Y., USA). P-values $<0.05$ were considered as statistically significant. To assess inter-rater agreement, Intraclass Correlation Coefficients (ICC) were calculated using all separate measurements ( 5 measurements in 50 grafts by 2 observers $=500$ measurements) and using a one-way model with the observers considered as random. Since the inter-observer agreement was high (see results), further analyses were done using only the measurements of the first observer per graft. Furthermore, since the inter-observer agreement on the thickness of the foil was very consistent (see results), all graft thickness data was analyzed after subtracting the mean value of the thickness of two foils. Average graft thickness was calculated by averaging the five measuring points for each graft. It was not possible to account for the variables that could have influenced graft thickness post-harvesting, so it was assumed that these variables would have a consistent effect on every graft.

To provide insight into shrinkage of the graft, post-harvest shrinkage was calculated by comparing the length of the donor wound and the length of the graft. The amount of shrinkage or stretching of the graft was not taken into account in the other analyses.

To test whether the average graft thickness did not differ from the thickness setting of the dermatome, a one-sample T-test was performed for each thickness setting $(0.20,0.25$ and $0.30 \mathrm{~mm})$.

Testing if the measured thickness was consistent across the grafts was done in two ways. The first was across the length of the graft, based on the clinical assumption that most surgeon's involuntary make a scooping motion with the dermatome during graft harvesting so that the proximally harvested part of the graft is thickest and the distally harvested part is thinnest. To test this assumption, a paired T-test was performed comparing the averaged two proximal and averaged two distal measuring points of each graft. Secondly, it was tested whether the measured thickness of the graft was consistent across the width of the grafts, based on the clinical assumption that the grafts would be thinner on the lateral sides than in the middle because the grafts are harvested by applying a straight blade on mostly curved surfaces (e.g. an upper leg). To test this, a paired $\mathrm{T}$-test was performed separately for each lateral side by comparing the averaged lateral measuring points to the measuring point in the middle of the grafts. All paired T-tests solely included the grafts that were harvested with the dial setting of $0.25 \mathrm{~mm}$, as this was the largest group. The groups with other dial settings were supposed to be too small to render interpretable results.

For analysis of the bluntness of the blade, the grafts with missing data on the length of the donor wound were excluded. Using the known length of the donor wound, it was noted for each measuring point how many centimeters of skin the blade had harvested already ('centimeters travelled'). A second variable was created: the dial setting minus the average thickness of the skin graft (without the foil), called the 'deviation' (from the dial setting). This new variable allowed us to study whether this deviation was constant or depended on the number of 'centimeters travelled' previously by the blade. It was assumed that a perfect blade would have a constant deviation regardless of the number of centimeters travelled and that an imperfect or blunt blade would show a more variable deviation. This assumption was tested as follows: the two proximal as well as the two distal measuring points of each graft were averaged. On these three lengthwise measuring points mixed-model linear regression analysis was performed to test the assumption of an ideal blade without bluntness: if the slope of the regression line was not statistically different from 0 , and the variability (i.e. heteroscedasticity) did not increase regardless of the number of centimeters travelled, the blade was assumed not to become blunt.

\section{Results}

Fifty grafts were collected from 30 patients (19 males and 11 females) with a mean age of 34.8 years (Standard Deviation [SD] 20.1; range 2-74). Four patients were children aged below 11 years.

The largest group of 33 grafts was harvested with a dial setting of $0.25 \mathrm{~mm}$ (Table 1). Most of these grafts (27/33) were harvested from the upper leg. Twelve grafts were harvested with a dial setting of 0.20 $\mathrm{mm}$ of which five from the scalp. Five grafts were harvested with a dial setting of $0.30 \mathrm{~mm}$.

In total, 8 grafts were harvested from the scalp, mostly in children and with a dial setting of $0.20 \mathrm{~mm}$.

The inter-observer agreement on graft thickness measurements was high, with an ICC of 0.96 (95\% confidence interval [CI] 0.95, 0.97). The inter-observer agreement on foil thickness measurements was also high, with an ICC of 0.90 (95\% CI 0.83, 0.94). Mean foil thickness of two layers was $0.11 \mathrm{~mm}$ (SD 0.01).

Graft length differed between harvest locations. Scalp grafts were shorter than grafts from other locations. The grafts had stretched or shrunk post-harvest up to $13 \%$ (Table 2). Most grafts harvested from the upper leg were longer than the donor wound length (i.e. they were stretched post-harvesting). Notably, grafts harvested from the scalp and other locations than the upper leg were on average shorter than the donor wound, which means that they had shrunk post-harvesting.

\section{Measured graft thickness: deviation from the dial setting}

The measured thickness of the grafts varied but seemed on average $50 \%$ thinner than the dial setting for the grafts harvested with settings $0.25 \mathrm{~mm}$ and $0.30 \mathrm{~mm}$ (Table 3 ). The average measured thickness differed significantly from the dial setting for the grafts harvested with dial settings $0.25 \mathrm{~mm}$ (deviation from dial setting: $95 \%$ CI $-0.14,-0.10$; $\mathrm{p}<0.0001$ ) and $0.30 \mathrm{~mm}$ (deviation from dial setting: 95\% CI-0.20, $-0.10 ; \mathrm{p}=0.001$ ).

Table 1: Graft characteristics by dial setting.

\begin{tabular}{|c|c|c|c|c|}
\hline & \multicolumn{3}{|c|}{ Dial setting of the dermatome } & \multirow[b]{2}{*}{$\begin{array}{l}\text { Total } \\
\mathrm{n}=50\end{array}$} \\
\hline & $\begin{array}{c}0.20 \mathrm{~mm} \\
\mathrm{n}=12\end{array}$ & $\begin{array}{c}0.25 \mathrm{~mm} \\
\mathrm{n}=33\end{array}$ & $\begin{array}{c}0.30 \mathrm{~mm} \\
\mathrm{n}=5\end{array}$ & \\
\hline Median age, (range) & $29(2-61)$ & $34(2-74)$ & $21(8-52)$ & $35(2-74)$ \\
\hline Children, $\mathrm{n}$ & 5 & 4 & 1 & 10 \\
\hline $\begin{array}{l}\text { Median graft length in } \mathrm{cm} \\
\text { (range) }\end{array}$ & $22(6-37)$ & $18(6-34)$ & $24(14-26)$ & $20(6-37)$ \\
\hline $\begin{array}{c}\text { Harvest location, } \mathbf{n} \\
\text { Scalp }\end{array}$ & 5 & 3 & 0 & 8 \\
\hline Upper leg: Lateral & 1 & 1 & 1 & 3 \\
\hline Upper leg: Medial & 3 & 21 & 1 & 25 \\
\hline Upper leg: Ventral & 0 & 5 & 2 & 7 \\
\hline $\begin{array}{l}\text { Other (armpit, thorax, upper } \\
\text { and lower arm) }\end{array}$ & 3 & 3 & 1 & 7 \\
\hline
\end{tabular}


Table 2: Association between graft length and length of the donor wound, by harvest location.

\begin{tabular}{|c|c|c|c|c|c|}
\hline & \multicolumn{5}{|c|}{ Harvest location of the graft } \\
\hline & $\begin{array}{c}\text { Scalp } \\
\mathrm{N}=8\end{array}$ & $\begin{array}{c}\text { Upper leg: } \\
\text { Lateral } \\
N=3\end{array}$ & Upper leg: Medial N=25 & Upper leg: Ventral $\mathrm{N}=7$ & Other $^{1} \mathrm{~N}=7$ \\
\hline Graft length in $\mathrm{cm}$, mean \pm SD (range) & $\begin{array}{c}6.3 \pm 0.6 \\
(6-7)\end{array}$ & $\begin{array}{c}30.7 \pm 8.6 \\
(23-40)\end{array}$ & $\begin{array}{c}21.7 \pm 8.7 \\
(8-38)\end{array}$ & $\begin{array}{c}24.2 \pm 7.2 \\
(14-31)\end{array}$ & $\begin{array}{c}12.5 \pm 6.7 \\
(6-21)\end{array}$ \\
\hline Length of donor wound in $\mathrm{cm}$, mean \pm SD (range) & $\begin{array}{c}6.7 \pm 1.2 \\
(6-8)\end{array}$ & $\begin{array}{c}27.3 \pm 8.5 \\
(21-37)\end{array}$ & $\begin{array}{c}19.6 \pm 7.5 \\
(8-34)\end{array}$ & $\begin{array}{c}22.0 \pm 5.9 \\
(13-29)\end{array}$ & $\begin{array}{c}13.5 \pm 7.1 \\
(6-22)\end{array}$ \\
\hline Average percentage of graft length post-harvest ${ }^{2}$ & $96 \%$ & $113 \%$ & $107 \%$ & $110 \%$ & $92 \%$ \\
\hline
\end{tabular}

${ }^{1}$ armpit, thorax, upper and lower arm.

${ }^{2}$ (post-harvesting graft length / length donor wound) $\times 100 ;<100 \%$ means that the harvested graft had shrunk, i.e. shorter than the donor wound, $>100 \%$ means that the harvested graft was stretched, i.e. longer than the donor wound.

Table 3: Mean thickness (Standard Deviation) for each of the five measuring points per graft, by dial setting of the dermatome and by harvest location of the graft.

\begin{tabular}{|c|c|c|c|c|c|c|c|}
\hline & & \multicolumn{6}{|c|}{ Measuring point of the skin graft } \\
\hline & & Proximal left & Proximal right & Middle & Distal left & Distal right & Average \\
\hline \multirow{3}{*}{ Thickness setting } & $\begin{array}{c}0.20 \mathrm{~mm} \\
(\mathrm{n}=12)\end{array}$ & $0.17(0.09)$ & $0.16(0.07)$ & $0.19(0.11)$ & $0.15(0.07)$ & $0.15(0.08)$ & $0.16(0.07)$ \\
\hline & $\begin{array}{c}0.25 \mathrm{~mm} \\
(\mathrm{n}=33)\end{array}$ & $0.14(0.07)$ & $0.13(0.07)$ & $0.13(0.07)$ & $0.12(0.06)$ & $0.11(0.06)$ & $0.13(0.05)$ \\
\hline & $\begin{array}{c}0.30 \mathrm{~mm} \\
(\mathrm{n}=5)\end{array}$ & $0.13(0.08)$ & $0.17(0.06)$ & $0.12(0.04)$ & $0.16(0.04)$ & $0.15(0.04)$ & $0.15(0.04)$ \\
\hline \multirow{4}{*}{ Harvest location } & Upper leg: lateral $(n=3)$ & $0.13(0.02)$ & $0.14(0.07)$ & $0.12(0.04)$ & $0.16(0.04)$ & $0.15(0.06)$ & $0.14(0.02)$ \\
\hline & $\begin{array}{c}\text { Upper leg: medial } \\
(n=25)\end{array}$ & $0.13(0.05)$ & $0.12(0.05)$ & $0.11(0.05)$ & $0.12(0.05)$ & $0.10(0.05)$ & $0.12(0.03)$ \\
\hline & $\begin{array}{l}\text { Upper leg: ventral } \\
\qquad(\mathrm{n}=7)\end{array}$ & $0.11(0.05)$ & $0.13(0.05)$ & $0.13(0.03)$ & $0.12(0.04)$ & $0.13(0.04)$ & $0.12(0.03)$ \\
\hline & $\begin{array}{l}\text { Other }^{1} \\
(n=7)\end{array}$ & $0.16(0.07)$ & $0.17(0.06)$ & $0.15(0.05)$ & $0.12(0.05)$ & $0.13(0.02)$ & $0.14(0.05)$ \\
\hline
\end{tabular}

${ }^{1}$ armpit, thorax, upper and lower arm.

For the grafts harvested with dial setting $0.2 \mathrm{~mm}$, no statistically significant deviation from the dial setting was found ( $95 \%$ CI -0.08 , $0.01 ; \mathrm{p}=0.11$ ).

The variability of the deviation from the dial setting was largest for scalp harvests with average deviation ranging from -0.16 to + $0.16 \mathrm{~mm}$ (Figure 3 ). The average measured thickness varied about $0.04 \mathrm{~mm}$ between two points on the same graft, with the Standard Deviation (SD) being about the same. This was slightly less than one dial setting (Table 3 ).

\section{Measured graft thickness: consistency across the grafts}

The paired T-test for analyzing if the thickness measurements were consistent across the length of the grafts did not show inconsistency: the mean difference between proximal and distal measurements was $0.02 \mathrm{~mm}$ ( $95 \% \mathrm{CI}-0.00,0.04 ; \mathrm{p}=0.09)$. The paired T-tests for analyzing the consistency of graft thickness across the width of the grafts also did not give significant results: mean difference left-middle $0 \mathrm{~mm}$ ( $95 \%$ CI- $0.00,0.01 ; \mathrm{p}=0.48)$, and mean right-middle $0 \mathrm{~mm}$ (95\% CI$0.01,0.01 ; \mathrm{p}=0.66)$. These results were interpreted so that the grafts were flat (i.e. not significantly scooped or concave in shape). There was variability in the measurements in both directions within the grafts (data not shown). Since the variability seemed largest for scalp grafts, paired T-tests were performed for the scalp group separately, which showed significant differences in graft thickness across the width of the grafts: mean difference left-middle $0.06 \mathrm{~mm}$ (95\% CI $0.01,0.10 ; \mathrm{p}=0.03$ ), mean difference right-middle $0.06 \mathrm{~mm}$ (CI 0.01 , $0.10 ; \mathrm{p}=0.02)$. However, no statistically significant differences in graft thickness across the length of the grafts were noted: mean difference $0.03 \mathrm{~mm}(95 \% \mathrm{CI}-0.02,0.08 ; \mathrm{p}=0.21)$. This means the scalp grafts were unevenly thick across the width, as the middle of the grafts was significantly thicker than the sides of the grafts.

\section{Measured graft thickness: effect of blade bluntness}

Thirty-eight grafts were included for the analysis of the bluntness of the blade. The regression coefficient for the distance travelled with

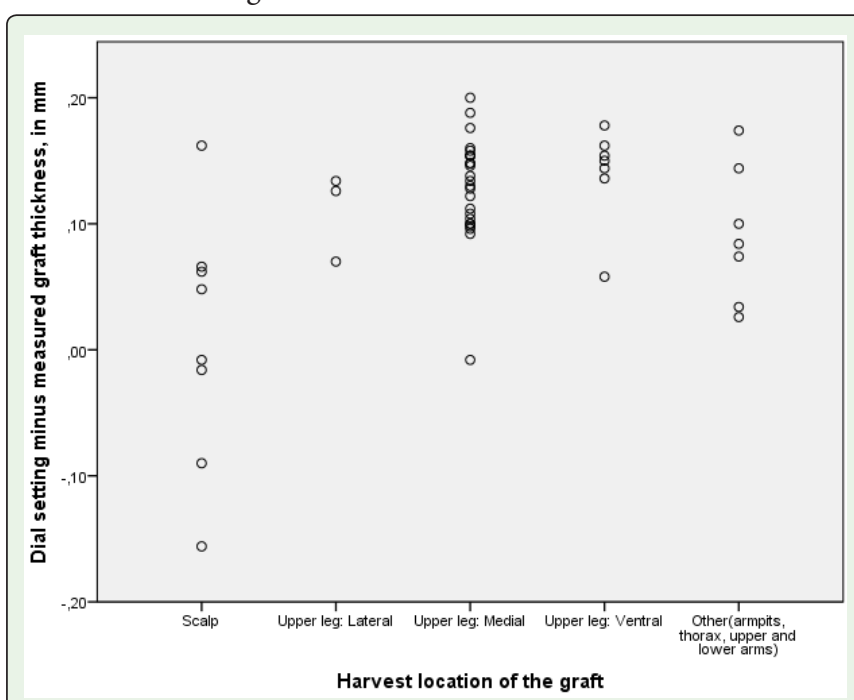

Figure 3: Difference between the dial setting and the average thickness measurement per graft, by harvest location. 
the same blade in the linear regression model did not significantly differ from 0 ( $\mathrm{p}=0.10)$, which means that the measured thickness did not increase or decrease with an increase in the number of centimeters travelled with the same blade. The slope of the regression line was also not statistically different from 0 in the mixed-model linear regression model when correcting for sequential grafts $\mathrm{P}=0.11$ (95\% CI -0.001 , 0.001). The harvested grafts were not significantly thicker or thinner regardless of the number of centimeters travelled; neither did the results become heteroscedastic regardless of centimeters travelled (i.e. variability did not increase). These results show that there was no impact on the accuracy of the blade caused by repeated use ('bluntness') of the blade.

\section{Discussion}

This exploratory observational study aimed to prove or disprove the ability of surgeons to harvest skin grafts with an average thickness that corresponds with the thickness setting of a Zimmer pneumatic II dermatome. Despite the limited number of 50 skin grafts, some of the results were noteworthy and allow for preliminary conclusions.

Firstly, the results of this study suggest that for the grafts harvested with the dial settings of 0.25 and $0.30 \mathrm{~mm}$ the measured values differed significantly from the thickness setting of the dermatome. However, we cannot be sure that the measured thickness is the same as the 'true' harvested thickness, since stretching or other unaccounted variables may have influenced the thickness of the graft once harvested. It stands out, however, that in the 0.25 and $0.30 \mathrm{~mm}$ dial setting groups, the measured average thickness was consistently half of the dial setting. It would seem that this difference is too large to be caused by variables that are unaccounted for, as the grafts were stretched and had shrunk up to $10 \%$ instead of up to $50 \%$. This would imply that there is an actual difference between the harvested thickness and the thickness setting. To be more precise, it would mean that the harvested grafts might be close to $50 \%$ thinner than the setting indicated on the dermatome. We chose not to correct our measured thickness data for shrinkage, as we do not know which variables in reality influence a graft post-harvest. Therefore, correcting for only shrinkage probably would not have made our results more valid.

Secondly, the measured thickness differed considerably for the grafts harvested from the scalp. Scalp grafts were between up to $50 \%$ thinner and to up $200 \%$ thicker as the dial setting. Scalp grafts also proved significantly thicker at the center of the graft compared to the edges. If scalp grafts are thicker than intended, this may increase the risk of adverse effects such as scar formation or alopecia at the donor site [6]. In a retrospective cohort of 93 burn patients (mostly children) who underwent scalp grafting in our clinic, no cases of scar formation or alopecia were seen [7].

Thirdly, the grafts from other locations than the scalp did not seem to be unevenly thick. In general, surgeons are very careful to harvest a flat graft by applying consistent force to the dermatome throughout the procedure and by flattening the skin before harvesting. It may either be that this modus operandi has positive results, or that it is not necessary to do so, which would make the procedure graft harvesting less time-consuming. These effects are difficult to quantify, but further research could help elucidate the matter. However, for now we conclude that the clinician may only need to account for a systematic error in harvested thickness in case of scalp grafts.
Fourthly, it is common practice to change the blade of the dermatome once every few grafts. However, our results suggest that this may not be necessary for a consistent graft thickness, as it seemed that there was no impact of the repeated use of the blades on the harvested thickness of the grafts (i.e. the grafts did not become thicker, nor did the variability in measured thickness increase).

An interesting consideration, which should be mentioned, is the possibly different elasticity of the skin taken from different donor site locations. Studies show that not only the age, but also part of the human body influences the skin elasticity [8]. In our study we saw a shrinking of the STSG taken from the scalp and from 'other' locations, in comparison with an enlargement of the STSG taken from the upper leg. The most reasonable explanation for the shrinking of the scalp skin might the beforehand stretched skin by infiltration with a saline solution. However, the contracting of the STSG taken from 'other' locations (armpit, thorax and arm) might be the effect of a more elastic skin in these regions.

Furthermore, systemic illnesses, as collagenopathies, might of course be of influence on the skin, and might have consequences for the thickness of the STSG and or scarring (of burn wound or donor site). None of our patients in this cohort was known with such a systemic disease. And so, this variable most probably has not been of influence on our results.

Some limitations of the study have to be mentioned. The data was collected using an analog, mechanical measuring device. Conceivably, another measuring device that does not put pressure on the graft may measure more accurately, but such a method has not yet been developed and will have its own limitations. However, another measuring device would most likely not change the consistency of the measurements and as such, would have no bearing on our findings regarding differences in graft thickness between harvest locations, the consistency of the graft thickness across grafts and the supposed bluntness of the blade. Furthermore, in the grafts in our study only a relatively small spectrum of thickness settings on the dermatome was used $(0.2$ to $0.3 \mathrm{~mm})$. As possible settings of the dermatome ranges from $0.1 \mathrm{~mm}$ to $0.6 \mathrm{~mm}$, a larger variability of settings may have rendered more striking results. However, the settings that were used in this study are the settings that are most commonly used in the clinical setting and therefore the most relevant.

\section{Conclusion}

In conclusion, the thickness of harvested skin grafts seems to be, on average, $50 \%$ thinner than the dial setting of a Zimmer II pneumatic dermatome. This result could be artificial and therefore be attributable to variables that are unaccounted for post-harvesting, although post-harvest shrinkage of the grafts does not seem an adequate explanation. Furthermore, the variability in graft thickness is much larger in scalp grafts than in grafts from other locations. Moreover, scalp grafts are significantly curved (i.e. the sides are thicker than the center). This result is clinically relevant for prevention of scar formation and alopecia. Grafts from other harvest locations were more even in thickness, so it seems that surgeons do not make a scooping motion when harvesting with a dermatome. Lastly, it does not seem necessary to change the blade of the dermatome as often, as it has no apparent impact on the harvested thickness. 


\section{Acknowledgements}

We would like to thank Dr. Ron Wolterbeek, biostatistician, for statistical support. The authors declare no conflict of interest.

\section{Notes:}

1. UrgoTul. Urgomedical Nederland.

2. Teclock SM-114. TECLOCK Corporation.

\section{References}

1. Adams DC, Ramsey ML. Grafts in dermatologic surgery: review and update on full- and split thickness skin grafts, free cartilage grafts, and composite grafts. Dermatol Surg. 2005; 31: 1055-1067.

2. Yamaguchi Y, Hosokawa K, Kawai K, Inoue K, Mizuno K, Takagi S, et al Involvement of keratinocyte activation phase in cutaneous graft healing: comparison of full-thickness and split-thickness skin grafts. Dermatol Surg. 2000; 26: 463-469
3. Tang YW. Simultaneous very thick split-thickness and split-thickness skin grafting for treating burned limbs. J Burn Care Res. 2010; 31: 822-825.

4. Housewright $C D$, Lenis $A$, Butler DF. Oscillating electric dermatome use for harvesting split-thickness skin grafts. Dermatol Surg. 2010; 36: 1179-1182.

5. Nakayama Y, Chuang YM. A scalpel blade as a substitute for the calibrator of the dermatome. Plast Reconstr Surg. 1983; 72: 405-407.

6. Chang LY, Yang JY, Chuang SS, Hsiao CW. Use of the scalp as a donor site for large burn wound coverage: review of 150 patients. World J Surg. 1998 22: $296-299$

7. Roodbergen DT, Vloemans AF, Rashaan ZM, Broertjes JC, Breederveld RS The scalp as a donor site for skin grafting in burns: retrospective study on complications. Burns Trauma. 2016; 4: 20

8. Ryu HS, Joo YH, Kim SO, Park KC, Youn SW. Influence of age and regional differences on skin elasticity as measured by the Cutometer. Skin Res Technol. 2008; 14: 354-358. 